\title{
A GESTÃO DO ENSINO SUPERIOR EM ANGOLA: PRÁTICAS E LÓGICAS DE ACESSO
}

\author{
Maria da Conceição Barbosa Mendes (UKB)* \\ Tuca Manuel $(U K B)^{* *}$ \\ https://orcid.org/0000-0003-2150-6687 \\ Isabel Maria Romero Fernandez de Carvalho (UKB)*** \\ https://orcid.org/0000-0002-5394-6989
}

\section{RESUMO}

Este trabalho sintetiza reflexões sobre a gestão do Ensino Superior (ES) em Angola, escrutinando as práticas e lógicas inerentes ao acesso. Os exames de acesso são trazidos ao palco, discutindo as suas configurações enquanto problemática de gestão, e a tendencial desarticulação entre estes e o perfil dos candidatos. A interpretação da Lei de Bases do Sistema de Educação e Ensino (LBSEE) e do Regulamento Geral de Acesso ao Ensino Superior constituiu-se procedimento metodológico fundamental, permitindo aferir a relação entre o referente e o referido, em termos do perfil de saída e de entrada. A identificação de desarticulações entre o Ensino Geral e o Ensino Superior, no que diz respeito aos perfis de saída e ao cumprimento dos objetivos pedagógicos, constitui o principal resultado do estudo, com base no qual foram apresentadas algumas alternativas.

Palavras-chave: Avaliação. Acesso ao ensino superior. Exames de acesso. Gestão. Perfil de entrada.

\section{ABSTRACT}

\section{HIGHER EDUCATION MANAGEMENT IN ANGOLA: ACCESS PRACTICES AND LOGICS}

This paper synthesizes reflections on the management of Higher Education (ES) in Angola, scrutinizing the practices and logic inherent in access. The entrance exams are brought to the stage, discussing their configurations as a management problem, and the tendency of disarticulation between them and the candidates' profile. The interpretation of the Basic Law of the Education

Doutora em Organização e Administração Escolar pelo Instituto de Educação da Universidade do Minho, Portugal. Professora Catedrática e Decana do Instituto Superior de Ciências da Educação da Universidade Katyavala Bwila, em Benguela. E-mail: saobarbosa67@yahoo.com.br

** Doutor em Organização e Administração Escolar pelo Instituto de Educação da Universidade do Minho, Portugal. Professor Colaborador do Instituto Superior de Ciências da Educação da Universidade Katyavala Bwila, Benguela. E-mail: tucamanuel12@ yahoo.com.br

*** Doutora em Psicologia Educativa e da Educação pela Universidade de València, Espanha. Professora Auxiliar e Vice-Decana do Instituto Superior de Ciências da Educação da Universidade Katyavala Bwila, em Benguela. E-mail: romeroisabel4@gmail.com 
and Teaching System (LBSEE) and the General Regulation of Access to Higher Education constituted a fundamental methodological procedure, allowing to assess the relation between the referent and the referred, in terms of the exit profile and input. The identification of disarticulation between the General and Higher Education, regarding the exit profiles and the fulfillment of the pedagogical objectives, constitutes the main result of the study, based on which some alternatives were presented.

Keywords: Evaluation. Access to higher education. Access exams. Management. Input Profile.

\section{RESUMEN}

\section{GESTIÓN DE LA EDUCACIÓN SUPERIOR EN ANGOLA: PRÁCTICAS Y LÓGICAS DE ACCESO}

Este artículo sintetiza reflexiones sobre la gestión de la Educación Superior (ES) en Angola, examinando las prácticas y la lógica inherentes al acceso. Los exámenes de ingreso se llevan al escenario, discutiendo sus configuraciones como un problema de gestión y la tendencia a la desarticulación entre ellos y el perfil de los candidatos. La interpretación de la Ley Básica del Sistema de Educación y Enseñanza (LBSEE) y el Reglamento General de Acceso a la Educación Superior fue un procedimiento metodológico fundamental, que permitió evaluar la relación entre el referente y el árbitro, en términos del perfil de salida y entrada. La identificación de la desarticulación entre la Educación General y Superior, en relación con los perfiles de salida y el cumplimiento de los objetivos pedagógicos, constituye el principal resultado del estudio, en base al cual se presentaron algunas alternativas.

Palabras clave: Evaluación. Acceso a la educación superior. Acceso a exámenes. Gestión. Perfil de entrada

\section{Introdução}

Da experiência precedente de acesso por via do sistema público de encaminhamentos a partir das escolas do ensino secundário durante o regime do Partido-Estado, ao mecanismo difuso em que os candidatos se sujeitavam à lógica do chacun a ses metieres, em decorrência da abertura à pluralidade política e à economia de mercado a partir de 1992, verifica-se uma consolidação da uniformidade de acesso por via de exames de aferição, independentemente das idades e das médias de conclusão do ensino secundário. No entanto, o elevado número de candidatos que termina o ensino secundário com as idades regulamentadas pelo sistema e que ficam de fora do subsistema do Ensino Superior (ES), bem como o hiato factual entre o mérito e a excelência documentados na conclusão do ensino secundário e o mérito no exame de acesso levantam questionamentos em relação às idades face à estrutura do sistema nacional do ensino, e a relevância curricular nos subsistemas precedentes face à sugestão de conteúdos que corporizam os exames de acesso.

A presente recensão procura desocultar as racionalidades subjacentes ao condicionamento dos méritos evocados pela Lei de Bases do Sistema de Educação e Ensino (LBSEE), artigo 
62ำ, Acesso ao ES (ANGOLA, 2016), e sua confrontação com a essência e objetivos desse subsistema, num ambiente em que o público e o privado concorrem para os mesmos públicos.

\section{Os méritos evocáveis para o acesso}

Encaramos, a priori, como um exercício desafiador abordar o acesso ao ES, de modo particular em Angola, devido à complexidade ontológica de contextos educacionais e da sua dinâmica configurada, especialmente pelo surgimento de diversas Instituições do Ensino Superior (IES) sujeitas à administração estatal e privada, bem como pela diversificação da oferta formativa. Tem sido reconhecido o alcance de resultados significativos em termos quantitativos (número de IES, quantidade de cursos e efetivos docente e discente), os progressos do subsistema são pouco perceptíveis, em termos qualitativos, do que emergem questionamentos quanto à qualidade do desempenho de todo o sistema nacional de educação e ensino (instituições, docentes, discentes e a disponibilidade de recursos pedagógicos).

Enquanto referenciais usados para fundamentar a formulação de políticas na pretensa busca permanente dos níveis de qualidade do desempenho das instituições escolares, as instituições, os docentes, os discentes e a disponibilidade de recursos pedagógicos constituem-se em indicadores credíveis para as opções de avaliação.

Num quadro em que o mérito da trajetória acadêmica no subsistema precedente é, muitas vezes, contrastado com o mérito do exame de acesso, a aferição da qualidade passa a basear-se em pressupostos posteriores, apesar do desequilíbrio da precedência. Tal não eximiu que a LBSEE estabelecesse, como um dos princípios gerais do sistema de educação, a "qualidade de serviços" - artigo 14을 Lei no 17/2016 (ANGOLA, 2016). Na sequência, a avaliação é reportada como uma ferramenta de gestão do Sistema Educativo, particularizando a apreciação da execução e da implementação dos objetivos e metas das instituições e do próprio sistema - $\mathrm{n}^{\mathrm{0}}$ 1, artigo 100ำ (ANGOLA, 2016) -, sem, contudo, escrutinar os usos múltiplos conferidos aos resultados das avaliações que, com frequência, transpõem as questões pedagógicas, enleando-se à determinação do valor das propinas e emolumentos.

Essa injunção factual a respeito do acesso ao ES tem-se constituído em base plausível para a estabilidade das IES, introduzindo, deste modo, um terceiro mérito, o econômico. Assim, a par do mérito da trajetória acadêmica no nível precedente e do mérito do exame de acesso, os ingressados no ES podem ser observados por essa tridimensionalidade acadêmico-econômica. Contudo, ao definir para o ES as dimensões, estruturas, níveis e estratégias da avaliação, mesmo evocando como objeto de regulamentação específica, perspectivando “[...] assegurar, de modo específico, a qualidade dos serviços prestados pelas Instituições de ES" - 3.ำ , preâmbulo, Decreto Presidencial n. $\mathrm{o}$ 203/2018 (ANGOLA, 2018) -, durante a formulação de indicadores de avaliação, a norma trespassa esta tridimensionalidade.

Será a complexidade de pilotar avaliações com indicadores compósitos devido à transdisciplinaridade e a interdisciplinaridade que recobrem o processo que levam a confirma-se a tênue transição da fase da expansão quantitativa para a qualitativa? Será suficiente a mobilização dos atores e de dispositivos técnicos, pedagógicos, financeiros e outros para compaginar as opções de avaliação às mudanças e exigências contextuais?

Havendo, em contexto geral do sistema educativo nacional, uma precedência de avaliações focadas para indicadores de centralidade quantificadora, a melhoria da qualidade das instituições, bem como a sua acreditação e a dos cursos ministrados, procura-se nesta fase associá-la à avaliação com indicadores qualificadores. Sendo essa uma componente que integra o processo formativo, que pode 
ser acionada como suporte para a aferição do grau de alcance dos objetivos estabelecidos com o centro na qualidade da formação que pode ser lida pela variação de habilidades, atitudes, capacidades, visões e perspectivas autonômicas dos formandos, tornando-se indispensável a sua abordagem com o devido rigor metodológico e técnico aquém das avaliações quantificadoras.

Percorrendo as múltiplas nuances da avaliação, consideramos os méritos estabelecidos pela LBSEE (percurso acadêmico do secundário e o exame de acesso) e o derivado da necessidade de sobrevivência das instituições (econômico) como fundamentos para uma reflexão construtivista assente nos seguintes pontos:

1. Os perfis e as exigências dos exames de acesso;

2. 0 atual modelo de acesso - incidências para a sustentabilidade das IES (vulnerabilizar e mitigar o mérito e sentido pedagógico dos exames);

3. A administração das IES e os vários públicos para o ES.

\section{Os perfis dos candidatos versus as exigências dos exames de}

\section{acesso}

Os exames de acesso têm sido acionados como mecanismos que visam aferir a compatibilidade do perfil dos candidatos face a determinados padrões mínimos, em termos de conhecimentos gerais e específicos, bem como competências para a frequência de determinada opção formativa.

Significa que o processo de seleção leva implícita a avaliação do rendimento acadêmico no nível de ensino precedente. Para isso, há que considerar determinados pressupostos didáticos e técnicos para a concepção das provas de exame. A comparabilidade implícita à avaliação requer, deste modo, o âmbito do referente e o do referido.
Como diz Hadgi (1994, p. 29), "para me poder pronunciar sobre uma dada realidade, devo dispor de uma norma, de uma grelha, à luz da qual a vou apreciar" uma determinada realidade observável, isto é, o referente. Assim sendo, o processo de análise ou de leitura do desempenho dos candidatos, isto é, a realidade observável, será o referido. Portanto, o exercício será estabelecer uma relação entre o conjunto de saberes que conformam o perfil dos candidatos e o que se espera deles.

Nesse processo estabelecido de confrontação do referente com o referido, poderão ocorrer as principais desarticulações e debilidades decorrentes da observância de indicadores (qualitativos e quantitativos), dos juízos morais e de injunções de natureza ideológica. Queremos significar que as prováveis desarticulações entre o requerido nos exames de acesso e o perfil real dos candidatos pode ser mais profundo do que aparenta ser. Há uma tríade de aspectos a considerar:

1. Os perfis mínimos requeridos, face às exigências implícitas à frequência do ES. Trata-se de um corpus de saberes (conceituais, procedimentais e atitudinais) corporizados numa aprendizagem integradora, enquanto condição didática para dar conta das exigências curriculares iniciais do ES;

2. Grau de exigência e de complexidade das provas de exame de acesso ao ES. Teoricamente procuram compatibilidade com os perfis mínimos requeridos, o que, na prática, pode destoar da realidade observável, isto é, do nível real dos candidatos;

3. Nível real dos perfis dos alunos do Ensino Secundário, isto é, dos candidatos, seja em termos de conhecimentos e de competências, seja em termos de compatibilidade entre a formação realizada no ensino secundário e a formação pretendida - no 2 do artigo $62^{\circ}$, Lei $\mathrm{n}^{\mathrm{o}}$ 17/2016 (ANGOLA, 2016). 
Apesar de a lei anunciar que "A articulação entre os conhecimentos e competências garantidos pelos diferentes subsistemas de ensino e o Sistema Nacional de Qualificações são objecto de regulamentação em diploma próprio" - artigo 19o da Lei no 17/2016 (ANGOLA, 2016) -, vivencia-se, na prática, um quadro que denuncia alguma desarticulação entre os conhecimentos e competências tendencialmente garantidos pelos diferentes subsistemas de ensino, particularizando o Subsistema de Ensino Geral e o do ES.

Ao existirem desarticulações entre os elementos elencados, criam-se condições favoráveis ao insucesso acadêmico, ao que se juntam questões pedagógicas mais específicas, que vão desde os aspetos inerentes à elaboração, à realização e à correção das provas de exame de acesso, em razão de critérios e exigências específicas.

Com a pretensão de identificar os possíveis parâmetros de aferição das exigências das provas de acesso no plano das intenções educativas, folheamos a LBSEE e identificamos as intenções que apontam a articulação, por via da avaliação, entre o Subsistema de ES e o de Ensino Geral, assumindo assim a avaliação como uma estrutura esporádica devido à ausência dos designados exames nacionais anuais.

A legislação estabelece, entre os determinantes para a seleção dos candidatos, o mérito e a excelência comprovados pela aplicação dos critérios do sistema de avaliação das aprendizagens na conclusão do ensino secundário - n⿳0 2 do artigo 62으, Lei no 17/2016 (ANGOLA, 2016) -, sem que os resultados da avaliação da conclusão do secundário fossem tomados no processo de seleção para o acesso, exceto, eventualmente, a especialidade. Era crível que as provas de acesso refletissem elementos e critérios de avaliação das aprendizagens do nível precedente. No entanto, obviamente, não poderá ser uma mera inclusão de critérios, mas uma articulação prática entre os conteúdos últimos do secundário e os introdutórios do terciário, entre uma perspectiva de tipologia das questões prescritivas e descritivas, para uma dimensão interpretativa e construtivista.

A necessidade de considerar os elementos mais profundos do sistema de avaliação das aprendizagens vem suscitando algumas questões como:

a) Até que ponto o sistema de avaliação das aprendizagens reflete critérios relacionados com a preparação do aluno para ingressar no Subsistema de ES? - ver objetivos gerais do II Ciclo do Ensino Secundário Geral, alínea b, artigo 33으, Lei n. 17/2016 (ANGOLA, 2016).

b) Partindo do pressuposto de que se avalia o que se ensina, de que modo o processo de ensino-aprendizagem é organizado e implementado para atender aos objetivos gerais estabelecidos para o II Ciclo do Ensino Secundário Geral?

c) Sob que condições pedagógicas se realiza o processo de ensino-aprendizagem?

Tendo como base os resultados dos exames de acesso, em nossa opinião, estamos perante um contexto que sinaliza, de modo isolado, algumas debilidades ao nível do sistema de avaliação das aprendizagens. No entanto, ao analisar os vários fatores que podem concorrer para esse estado de coisas, podemos extrapolar o nível micro da avaliação das aprendizagens e nos situarmos em um nível mais amplo, o da avaliação do próprio Sistema de Educação e Ensino, incluindo a avaliação de cada um dos distintos dispositivos que o conformam, desde os do âmbito do currículo, do corpo docente, dos alunos, dos recursos, entre outros, e podemos antever a possibilidade de a vítima estar a ser transformada em ré.

A serem identificadas algumas insuficiências do sistema educativo nacional pelo Ministro de Estado e da Casa Civil no seu discurso de abertura do presente ano acadêmico, percebe-se que as causas essenciais se relacionam com a qualidade do corpo docente, com as pedagogias, incluindo a consistência dos programas curriculares. Ora, para descortinar esta realidade e trazer ao palco as causas-raiz, implica acionar processos e mecanismos de 
introspecção institucional a todos os níveis, devido ao centralismo decisional que sustenta as estruturas dos distintos subsistemas que enformam o sistema nacional de educação. É a partir da lógica da administração educacional centralizada que brota o enredo de possíveis constrangimentos que viciam a qualidade do ensino nacional.

Alguns segmentos de acadêmicos defende a imprescindibilidade da avaliação devido à multidimensionalidade que encerra, quer seja em termos do seu objeto, das finalidades ou da diversidade de olhares, do ponto de vista interno e externo, porém, a geração de indicadores compósitos que incorporam os níveis macrossociológicos da administração educacional vem sendo enviesada pelo percurso socioprofissional e acadêmico de muitos decisores de topo. Com frequência, experimentam-se avaliações funcionalistas e instrumentais de pendor formalista, contrariamente às interpretativas e socioconstrutivistas de pendor emancipatório devido, representativamente, à constituição das equipes de pilotagem dessas mesmas avaliações, com base nas funções detidas nas estruturas institucionais do sistema educativo, em vez daqueles com perícia desenvolvida e experienciada autonomamente. Isto é, atores exercendo nas instituições unicamente funções técnicas devido à sua liberdade prévia e autonomia individual.

Como consequência dessa caraterização (formalismo avaliativo), o país confronta-se ainda com a ausência de referenciais nacionais sobre a situação real do processo formativo e do próprio desempenho de cada uma das instituições educativas, que podiam ser fornecidos pelas dimensões de avaliação interna e externa, podendo tal complexificar muito mais as tentativas de solução dos problemas inerentes aos perfis e às exigências dos exames. Via de solução, uniformização com todos os seus deméritos.

É tendencialmente um paradoxo pretender um regime de acesso geral ao ES sem a incorporação dos elementos de suporte. Queremos conferir relevo ao conjunto de informações sobre os reais resultados de aprendizagem, que permitam aferir os possíveis hiatos entre a situação atual e a situação desejada. A avaliação de cursos, de programas curriculares, das próprias instituições educativas pode ser acionada para a produção de um quadro real sobre os processos e resultados educacionais e acadêmicos, sem excluir a própria avaliação do sistema como um todo. Estes, por um lado, constituiriam os referenciais para a construção dos exames de acesso; e por outro, para a estruturação de políticas específicas para a correção dos possíveis hiatos.

A mera compatibilização dos exames de acesso num quadro em que os candidatos encontram-se em situações reais diferenciadas, em termos de saberes, poderá ser um risco perante os desafios atuais inerentes à melhoria da qualidade formativa, já que essa compatibilização poderia significar baixar ou elevar os níveis de exigência dos padrões mínimos de acesso, dependentemente do nível de rigor do ordenador.

Reiteramos que a inexistência de referenciais nacionais especificadores do que realmente conforma o estado atual relativo aos objetivos pedagógicos do Ensino Secundário, e não só, constitui a priori um elemento que dificulta qualquer exercício de compatibilização, ou de ajustamento do tipo e das exigências das provas de exame de acesso ao ES.

Num âmbito mais específico, a avaliação implícita aos procedimentos de acesso assume um caráter seletivo, o que é reforçado pela existência de numerus clausus, instaurando a competitividade. A configuração da avaliação nesta matriz não deixa de requerer a necessária elaboração metodológica e técnica dos instrumentos, procurando com isso algum rigor e um certo sentido de justiça para o próprio processo, sendo expetável que os melhores sejam selecionados. Para que tal aconteça, impõem-se o adequado controle das principais variáveis que intervêm na avaliação, desde as de ordem didático-metodológicas às mais subjetivas. 
São analisáveis, igualmente, as condições pedagógicas para a realização das provas de exame num clima em que as tensões de ordem emocional, entre as quais o stress, são iminentes, influenciando sobremaneira o desempenho dos candidatos em decorrência dos níveis de ansiedade devido à competitividade que o processo enforma. No caso do stress, este pode resultar num desequilíbrio entre as exigências e os recursos para lidar com as exigências específicas (LAZARUS; FOLKMAN, 1984). Assim, no decorrer do exame de acesso, os resultados podem ser influenciados negativamente por estas variáveis, independentemente do nível de cognição do candidato face às temáticas implícitas à prova de acesso.

Outro aspecto a considerar está ligado à motivação para a escolha do curso. Da análise efetuada ao questionário aplicado aos estudantes (do curso de Educação Primária, Ensino da Psicologia e Educação Especial do Instituto Superior de Ciências da Educação de Benguela), como se pode verificar na Figura 1, a maior parte destes escolheu o curso por ter afinidade com a docência, gostarem de trabalhar com crianças e para dar continuidade à formação média. Os pais e os professores são agentes influenciadores na eleição do curso. Um grupo de alunos elegeu a opção formativa apenas para dar continuidade aos estudos. Esta eleição pode resultar em decepção e, consequentemente, em reprovações consecutivas ou em abandono escolar. Apesar de representar apenas 1\%, preocupa-nos o caso em que a eleição do curso é uma forma de responder a alguma violência sofrida no ensino primário. Neste caso, trata-se da escolha do curso por fatores situacionais.

Figura 1 - Motivação para a escolha do curso

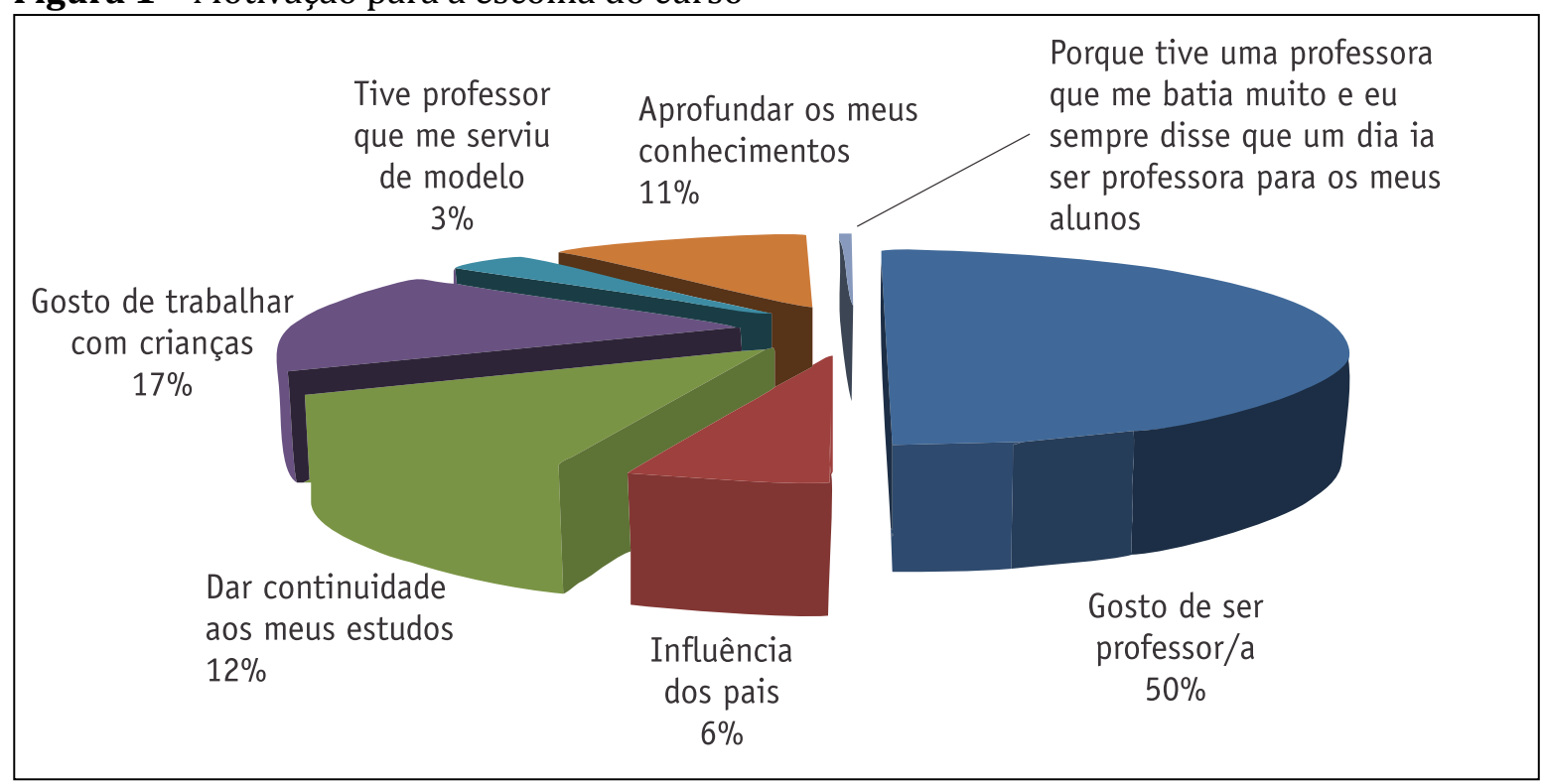

Fonte: Questionário aplicado em 2019 aos recém ingressados no ES.

A resposta produzida pelo candidato pode ser correta, mas tal não significa que ele tenha incorporado a lógica a partir do enunciado. Ou seja, não porque tenha "compreendido e resolvido o problema”, não porque tenha aprendido previamente, mas simplesmente porque estabeleceu uma semelhança com outro exercício e reproduziu, na sequência, uma solução já feita por outros para ele (D’AMORE, 2007, p. 191). Bittar (2017) defende por este fato que a Teoria Antropológica do Didático podia constituir-se numa ferramenta metodológica necessária para a análise de livros didáticos. Isto é, a necessidade de aferir a transição didática como a necessária em contraposição à certeza da resposta.

Em síntese, percebe-se que a aferição dos resultados das aprendizagens é um processo complexo em razão dos níveis diferenciados de conhecimentos precedentes dos candida- 
tos face à compatibilização requerida para os exames, entre outros fatores que intervêm. Por este fato, para além das medidas de natureza mais pedagógica e técnica, o estabelecimento de normas fundadas numa realidade objetivamente conhecida em sede de intencionais avaliações socioconstrutivistas precedentes pode ser visto também como um elemento regulador do processo. Por isso, procuramos incluir análises sobre o atual modelo de gestão do acesso nas nossas abordagens, tendo como base o respectivo regulamento geral.

\section{0 atual modelo de acesso: incidências para a sustentabilidade das IES}

Estando regulamentado no país que o acesso ao ES se sujeita a exames de aferição de conhecimentos de base, independentemente da natureza da administração pública educacional a que as instituições se sujeitem (estatal ou privada), a geração da compreensão integral do processo passa por desocultar os procedimentos e as racionalidades partilhadas. Há uma constatação preliminar de um contexto educacional desprovido, de modo geral, de processos e práticas sistemáticas de avaliação dos dispositivos que conformam o Sistema de Educação e Ensino, como sejam os programas curriculares, os ciclos formativos e as próprias escolas. Tal propicia de certa forma a emergência de desconexões entre os elementos que fundam a articulação sistêmica que enforma os dispositivos precedentes e os subsequentes, na perspectiva de manter a integridade e a sustentabilidade dos processos de administração educativa.

0 atual Regulamento Geral de Acesso ao ES - Decreto Presidencial n. ${ }^{\circ}$ 5/2019 (ANGOLA, 2019) -, é visto como um instrumento de regulação específica e com o potencial de responder, marcadamente, uma determinação legal nos termos do artigo 62. da LBSEE. Apesar de encerrar-se como detendo um caráter inédito, por ser o primeiro instrutivo legal sobre essa matéria específica no contexto do ES em Angola. Ao aplicar-se simultaneamente às instituições públicas e privadas, o regulamento não desprovê incidências de os ingressados no ES constituírem uma significativa fonte de sustentabilidade das IES, essencialmente as privadas.

Assim, a prescrição eivada pelo isomorfismo em todas as suas tipologias, levará à (re) construção de uma realidade, pragmaticamente, distante das aspirações da sociedade, salvo ao arrepio da lei, devido à ausência de avaliações socioconstrutivistas sistemáticas. Se o isomorfismo normativo procurou valorizar imperativos de previsibilidade, independentemente da relevância e da legitimidade social da norma em nome do mimetismo legislativo, à imagem e semelhança de outros contextos, os atores das IES, na perspectiva de verem as suas instituições sustentáveis, adotarão um conjunto de padrões visando responder às incertezas contextuais por via da imitação. $\mathrm{Ou}$ seja, às pressões expressas e tácitas, formais e informais exercidas, eivadas pela racionalidade burocrática, as IES responderão mediante a socialização consubstanciada no isomorfismo coercitivo, mecanismo irrepreensível de adequação à regulamentação sem comprometer a sustentabilidade das instituições.

Não bastará o mérito do exame de acesso conforme o regulamentado, mas o sentido de oportunidade, a coerência interna e a cobertura, valendo-se dos elementos e de procedimentos gerais legislados tendentes a gestão, a estruturação e a operacionalização do processo de acesso ao ES. Será pouco crível que a epistemologia escolar monumentalista que recobre na maior parte dos exames remeta as instituições a taxas de não cobertura estudantil que comprometam a existência e o funcionamento das instituições. Arquiteturas de gestão para inserir o maior número possível de estudantes serão tomadas, salvo por ingenuidade instrumental. É uma forma de compensar os investimentos requeridos ao funcionamento das IES. 
A existência de instâncias com vários níveis de intervenção, como a comissão nacional de acesso e a comissão institucional (ao nível das IES), sinaliza uma lógica de conformação do processo baseada em princípios de harmonização e de participação que podem contribuir para reduzir disparidades e construir parâmetros gerais de comparabilidade, num quadro em que o Sistema Nacional de Educação e de Ensino é caraterizado pela administração pública estatal, público-privada e pública comparticipada. Apesar de o ES não praticar esta última modalidade, os candidatos a ingressar provêm de subsistemas assim corporizados.

Há evidências da implantação de mecanismos de articulação entre a tutela e as unidades organizativas das IES e destas com estruturas das respetivas Unidades Orgânicas, cuja consistência é pouco refletida em relação às instituições privadas que mesmo advogando representativamente as infraestruturas, "a matéria-prima" candidatos constituiriam uma fonte incontornável de aferição da qualidade dessa natureza de IES. Isto configuraria dinâmicas de participação e de socialização entre os diversos intervenientes diretos do processo (público e privado) mediante processos sistemáticos de avaliação e de desencadeamento de processos de pensamento estratégico que se consubstanciariam em programas de desenvolvimento institucional.

Teria sido essa a via em que os conteúdos são visitados durante a formação e sua real finalidade e aplicação passaria a ser compreendida aquém do discurso ideológico. Por este motivo, a articulação também se reporta aos subsistemas, sendo determinada a compatibilidade entre o curso pretendido e a área correspondente do Ensino Secundário, visto no n 2 do artigo 6으 (ANGOLA, 2019).

Entendemos que a harmonização não devia ser vista num sentido de estandardização, mas sim como uma via de regulação do processo e de aproximação de critérios interpretativos para a comparabilidade. Tal implicaria o respeito a margens de diferenciação, dando espaço à contextualização, evitando a reprodução de conteúdos sem a compreensão de sua aplicação, o que podia proporcionar uma fraude epistemológica (CHEVALLARD, 1998). É neste sentido que Lima (2011), ao referir-se à avaliação, defende a observância de um mínimo de convergência sistémica para a transição da convergência normativa para a divergência competitiva e diferenciadora.

As fontes econômicas das IES têm estado a determinar, grandemente, a legitimidade do atual modelo de acesso. Porque se as IES públicas dependentes do orçamento geral do Estado podem fazer jus ao determinismo normativo para os cursos regulares, as privadas e os cursos do pós-regular das instituições públicas tenderão a configurar algum ecletismo em termos de critérios, como meio para a sua própria sobrevivência. Se num passado recente as IES privadas submetiam os candidatos a exames de acesso depois que as públicas tivessem terminado, tal significava que os não absorvidos pelas IES públicas encontravam nas privadas uma alternativa.

0 regulamento estabelece, pelo menos no plano das intenções, a salvaguarda de requisitos mínimos para a funcionalidade dos cursos, bem como as condições técnico-pedagógicas para o estabelecimento de vagas - $\mathrm{n}^{\underline{\mathrm{os}}} 2,3 \mathrm{e}$ 4 do artigo 5o do DP n 5/2019 (ANGOLA, 2019). Todavia, a simultaneidade dos exames de acesso a nível nacional e a autorização de segundas chamadas para os cursos cujos domínios científicos figuram como prioritários no Plano Nacional de Formação de Quadros - n⿳丷ㅜ 3 do artigo 18을 do DP no 5/2019 (ANGOLA, 2019) - gera brechas que podem reduzir o mérito da norma, por via do abrandamento do rigor pedagógico.

\section{A administração das IES e os vários públicos}

Considerando as descrições sustentadas por alguns referenciais pragmáticos e legislativos, é possível deslindar algumas pistas sob a for- 
ma de reflexões e alternativas relativamente à administração e os vários públicos para o ES, nomeadamente o perfil de entrada, a competitividade do acesso e as pressões decorrentes do estabelecimento de numerus clausus.

Ingressar no ES parece constituir-se num objetivo superior de muitos angolanos para o alcance de um determinado status socioeconômico, político e, eventualmente, cultural. A realidade aponta para o fato de a supremacia do setor público no mercado do emprego e a proeminência dos diplomas para aferir tratamento social e remuneração constituírem-se em fatores condicionadores da eficácia e da eficiência da administração das IES. Entretanto, escassamente os seus atores prestam-se a reforçar o status cultural dos ingressados em decorrência da própria estrutura organizacional e de gradação enredada pela regra do funcionalismo público.

Não importa a especialidade e a trajetória acadêmica precedentes, aceder a um curso do ES mesmo sem referenciar a vocação é a premissa maior. Policiais, militares, operários qualificados, e na maior parte dos casos, tecnicamente irrepreensíveis em diversas especialidades, ingressam em cursos pouco ou nada significativos para si e para o país, mas importa as consequências com a obtenção do diploma.

Submeter os candidatos a exames de acesso pode formalmente justificar a aferição do perfil prévio, mas a atenção à sustentabilidade das próprias instituições não pode ser ignorada.

Chevallard (1998), ao definir como tema central da teoria antropológica do didático os saberes e as instituições, procura incorporar a ideia de interdependência em que os saberes não são suficientes para aferir a dignidade das instituições e, por sua vez, estas não serão igualmente tão legítimas para aferir os saberes. 0 estabelecimento dos designados "o mercado das explicações" enquanto modelos sociais recorridos pelas famílias e alunos como apoios extraescolares refletem, de certa forma, os hiatos entre os saberes e as instituições frequentadas precedentemente pelos candidatos, podendo sinalizar algumas desarticulações entre os subsistemas do ensino nacional.

Assim, se considerarmos e assumirmos a existência de algumas debilidades e desarticulações dos subsistemas de ensino, será lógico defendermos a intervenção combinada das instituições educativas (escolas, famílias e sociedade em geral) a fim de se reduzirem as pressões sobre as famílias e alunos, propondo a estruturação de mecanismos e de iniciativas de apoio pedagógico à preparação dos alunos para o acesso ao ES. As concepções para o avanço subsumem-se nas generalizações e na lógica de confiança institucional, como interroga Lima (2008, p. 83): "Não somos todos, afinal, pesquisadores em educação, para além de longamente escolarizados e, por essas razões, conhecedores profundos da escola?"

Para o lato senso instrumental, o saber ler e escrever induz à existência de um professor. A existência de um professor induz à existência de um gestor ou administrador. No entanto, o processo educacional enredado pelas entradas e saídas e pelas diversas perspectivações da escola real implicam atenção aos fenômenos, os efeitos da instrumentalização e aos alcances da sociocrítica.

Que gestor/administrador de IES privada ou estatal na modalidade do pós-laboral se comprazeria com a não efetivação do numerus clausus em termos de entradas, como consequência do demérito em exames de acesso? 0 choque entre a ética e a norma pode ser pouco observado, mas justificará as opções estratégicas para rentabilizar o quadro docente, o pessoal administrativo e os equipamentos escolares. Uma realidade que o normativismo procura abster-se de clarificar, ou deixa margens claras de oportunismo e de desconfiança institucional.

Os apoios pedagógicos vão além da promoção do sucesso no exame de acesso. Pensamos em medidas que venham a permitir a superação das debilidades ao nível do próprio processo formativo, visando garantir que os perfis de saída estabelecidos para cada classe, 
curso e de cada subsistema sejam, de fato alcançados. Senão estaremos a perpetuar a mediocridade em detrimento de qualquer esforço para a garantia e a promoção permanente da qualidade, sem descurar, obviamente, que estas estratégias extraescolares podem constituir-se em importantes albergues de modalidades em que se coligem as explicações aos tópicos dos exames de acesso a ministrar.

Num plano amplo, as opções fundamentais da política educativa requerem dinâmicas que não se resumem na sua elaboração. A incorporação, nessas dinâmicas, de ações concretas que permitem transitar do plano normativo para o plano pragmático implica igualmente locomover-se da concepção instrumental à socioconstrutivista das IES. Só assim estas ações permitiriam examinar tanto a coerência de cada um dos elementos estruturantes da política, como a sua implementação. Ao estabelecer a imperiosidade de se "avaliar a execução e a implementação dos objetivos e metas das instituições e do Sistema de educação e Ensino, nos termos a regulamentar em diploma próprio para cada subsistema de ensino" - no 1 , artigo 100을 Lei no 17/2016 (ANGOLA, 2016) -, a LBSEE procura cobrir eventuais zonas de ambiguidade que emerjam no plano de ação.

\section{Considerações finais}

Do mérito da trajetória acadêmica ao mérito do exame de acesso, impõe-se desocultar a organização e funcionamento das instituições que conformam o sistema nacional do ensino, com vista a assegurar que o seu mérito retrate e seja retratado na regulamentação afim.

A pretensão é de destacar a adoção de dispositivos de avaliação que forneçam informações relevantes sobre o plano das intenções e o plano da realização prática das políticas educativas, sem eximir-se das infidelidades normativas enquanto fórmulas de adequação à realidade em face às desconexões normativas.

Num plano mais restrito, há que desencadear estudos que permitam um melhor conhe- cimento e compreensão das causas dos baixos índices de aproveitamento acadêmico, a partir dos quais será possível identificar medidas estratégicas para a sua superação.

Os exames nacionais que têm sido adotados em outros Estados como um mecanismo de regulação do sistema que salvaguarda a necessária articulação sistémica, implícita ao princípio da harmonização, podem ser adotados no caso angolano na perspectiva de reforçar o sentido nacional e sistêmico da educação e do ensino no país.

\section{REFERÊNCIAS}

ANGOLA. Presidência da República. Decreto Presidencial no 203, de 30 de agosto de 2018. Estabelece o Regime Jurídico de Avaliação e Acreditação da Qualidade das Instituições de ES. Diário da República de Angola, Luanda, I Série no 133, ago. 2018.

ANGOLA. Presidência da República. Decreto Presidencial no 5, de 8 de janeiro de 2019. Aprova o Regulamento Geral de Acesso ao ES. Diário da República de Angola, Luanda, I Série - no 3, jan. 2019.

ANGOLA. Assembleia Nacional. Lei no 17, de 7 de outubro de 2016. Lei de Bases do Sistema de Educação e Ensino, que estabelece os princípios e as bases gerais do Sistema de Educação e Ensino. Revoga a Lei no 13/2001, de 31 de dezembro de 2001. Diário da República de Angola, Luanda, I Série - no 170, out. 2016.

BITTAR, M. A teoria antropológica do didático como ferramenta metodológica para análise de livros didáticos. Zetetiké, Campinas, SP, v. 25, n. 3, p. 364-387, set./dez. 2017. Disponível em: https://periodicos.sbu.unicamp.br/ojs/index.php/ zetetike/article/view/8648640/17410. Acesso em: 29 mar. 2019.

CHEVALLARD, Y. Organisations didactiques: 1. Les cadres généraux. Notice du Dictionnaire de Didactique des Mathématiques 1997-1998 pour la formation des élèves professeurs de mathématiques. 1998.

D'AMORE, B. Epistemologia, didática da matemática e práticas de ensino. Bolema, Rio Claro, SP, v. 20, n²8, p. 1179-1205, 2007.

HADGI, C. A avaliação, regras do jogo: das 
intenções aos instrumentos. Porto, PT: Porto Editora, 1994.

LAZARUS, R. S.; FOLKMAN, S. Stress, appraisal and coping. New York: Springer, 1984.

LIMA, L. C. A escola como categoria na pesquisa em educação. São Leopoldo, RS: Educação Unisinos, 2008.
LIMA, L. C. Avaliação, competitividade e hiperburocracia. In: ALVES, M. P.; DE KETELE, J-M. (org.). Do currículo à avaliação, da avaliação ao currículo. Porto: Porto Editora, 2011. p. 71-82.

Recebido em: 24/03/2019

Aprovado em: 20/07/2019 